\title{
Exfoliative Endometrial Cytology in Embryo Donor Cows-Comparison of Sampling Localizations for the Diagnosis of Subclinical Endometritis
}

\author{
Janna Egberts ${ }^{1,2, *}$, Jan Detterer ${ }^{1}$, Arno Park ${ }^{1}$ and Sabine Meinecke-Tillmann ${ }^{2}$ \\ 1 AI- and ET-Center Georgsheil, VOST, Am Bahndamm 4, Südbrookmerland 26624, Germany; \\ j.detterer@vost.de (J.D.); a.park@vost.de (A.P.) \\ 2 Institute for Reproductive Biology, University of Veterinary Medicine Hannover, Bünteweg 2, \\ Hannover 30559, Germany; sabine.meinecke-tillmann@tiho-hannover.de \\ * Correspondence: j.egberts@vost.de; Tel.: +49-491-8004-327 \\ Academic Editor: Patrick Butaye \\ Received: 2 September 2016; Accepted: 23 November 2016; Published: 28 November 2016
}

\begin{abstract}
Subclinical endometritis has a major effect on the reproductive performance of dairy cows and also on the success of embryo collection. Thus it is important to minimize the number of false-negative diagnoses. In order to evaluate the question of whether or not a single cytobrush sample is representative of the whole endometrium, 53 German Holstein embryo donor cows in the northwest of Germany were examined via the cytobrush method at three different localizations of the uterus: the uterine body about $0.5 \mathrm{~cm}$ cranial of the cervical canal and both uterine horns about $1.5 \mathrm{~cm}$ cranial of the bifurcation. Although the mean percentage of polymorphonuclear neutrophils at the three locations is not significantly different $(p=0.64)$, the individual variations lead to the conclusion that more than one sample of the endometrium should be taken into account when diagnosing subclinical endometritis in embryo donor cows.
\end{abstract}

Keywords: exfoliative cytology; cytobrush; subclinical endometritis; dairy cows; embryo donor cows; PMN

\section{Introduction}

Subclinical endometritis (SE) is defined as a postpartum inflammation of the endometrium in the absence of any signs of clinical endometritis such as purulent vaginal discharge [1]. In order to diagnose SE, the proportion of polymorphonuclear neutrophils (PMN) in endometrial samples is evaluated.

Endometrial cytology has been proven to be a reliable method to detect SE, whereas bacteriological testing is not recommended since SE seems to be more of a problem of the recovery of the uterus postpartum than an infection [1-7]. Due to the impact of estrus cyclity, including the infiltration of PMN, which is lower on superficial compared to deeper layers of the endometrium, uterine biopsies are more sensitive to physiological changes than endometrial cytology $[8,9]$. Hence it is recognized that there is low correlation between endometrial biopsies and exfoliative cytology for diagnosing uterine disease [5].

Although there is no gold standard for the diagnosis of SE, cytobrushing has been used in the majority of studies and has been considered to be reliable, quick and easy [2,4-6,9-11] in contrast to low-volume flush $[3,12]$. Samples are taken from the most superficial layers of the endometrium, which makes cytobrushing insensitive to changes during the estrus cycle [5], which results in a reduction of false-positive outcomes. However, so far, and without regard to the possibility of localized events, cytobrush samples are mainly taken from a single intrauterine localization, based on the 
assumption that the diagnostic conditions would not differ throughout the whole endometrium, which has been reported for endometrial biopsies [13].

SE in cattle affects the reproductive performance as far as increasing the interval between calving and conception by about 30 days and decreasing the pregnancy rate by about $16 \%$ [1,3-5]. This results in major economic losses. An influence on the success of embryo collection has also been reported, where more unfertilized oocytes and fewer transferable embryos of poorer quality are collected from cows suffering from SE compared to healthy donor cows [10,11].

To allow for the proper management of those animals and to improve the success of embryo collection, it is important that the number of false-negative diagnoses is minimized.

The aim of this study was to answer the question of whether a cytological smear preparation taken from a single intrauterine localization is representative of the whole endometrium.

\section{Materials and Methods}

Fifty-three German Holstein cows in their first to tenth lactation $(4.3 \pm 1.8$ lactations/animal; means \pm SD) were investigated between D 64 and 1018 postpartum (D $215 \pm 165$ p.p.; means \pm SD). The animals (client-owned: informed client-consent) were presented as embryo donors in a commercial embryo transfer program. Before superovulation, all participants were clinically examined during interoestrus (D 6-13 of the oestrus cycle). With regard to standard transrectal palpation and ultrasound scanning (Easi-Scan ${ }^{\circledR}$, BCF $^{\mathrm{TM}}$ Technology, broadband straight linear rectal probe, $7.5 \mathrm{MHz}$ ) of the reproductive tract as well as vaginoscopic inspection of the vagina and external os of the cervix showed no signs of clinical illness.

Exfoliative cytology samples were obtained with commercial cytobrushes $\left(G y n o b r u s h{ }^{\circledR}\right.$, Heinz Herenz Medizinalbedarf $\mathrm{GmbH}$, Hamburg, Germany), which had been attached to a universal A.I. gun without mandrin (Kombicolor, IMV, L'Aigle, France). These extended cytobrushes had a total length of $54 \mathrm{~cm}$. In order to expose only the head of the cytobrush to the desired location of the endometrium, sterile casing aluminum pipes ( $47 \mathrm{~cm}$ long, outer diameter: $6 \mathrm{~mm}$, inner diameter: $4 \mathrm{~mm}$ ) with rounded tips were used to pass the cervix and to reach the desired intrauterine locations under transrectal control. To protect the sample from vaginal contamination and to ensure a clean sampling system to pass the cervix the whole system was placed in an A.I. sanitary sheath (IMV, L'Aigle, France), which was only perforated directly in front of the external os of the cervix.

Exfoliative cytology samples were taken by two experienced examiners from three different uterine localizations per animal, including both uterine horns about $1.5 \mathrm{~cm}$ cranial of the bifurcation and the uterine body about $0.5 \mathrm{~cm}$ cranial of the internal os of the cervix (standardized conditions). These localizations were chosen referring to the regions of interest in an ultrasonic echotexture study of the bovine uterus [14]. Sampling started in the uterine body (UB), followed by the right (RUH) and left uterine horn (LUH), each time with a fresh sampling system. The obtained cellular material was spread out on microscope slides, air dried, fixed, stained with DiffQuick ${ }^{\circledR}$ and covered with a HistoKitt ${ }^{\circledR}$ fixed cover glass. A total of 300 cells/slide were differentiated microscopically (light microscope, $400 \times$ magnification, Olympus, BH-2, Tokyo, Japan) by a single skilled investigator and the percentage of PMN was assessed [6]. The threshold level of PMN indicating SE was set at 5\% [6,15]. A total of 159 microscopic slides were investigated.

All results are displayed with means \pm SD. Statistical analysis was done using One Way Analysis of Variance on Ranks with InStat3 (GraphPad Software, Inc., La Jolla, California, USA).

\section{Results}

The mean percentage of PMN found throughout all differentiated smears was $2.4 \% \pm 1.7 \%$. Although statistically not significant $(p=0.64)$, the mean percentage of PMN found in the uterine body $(2.2 \% \pm 1.8 \%)$ was generally lower than in the right $(2.3 \% \pm 1.5 \%)$ and left uterine horns $(2.5 \% \pm 1.7 \%)$.

In 13 smears the PMN threshold of 5\% was exceeded, and $18.9 \%(10 / 53)$ of the cows were diagnosed with SE. Intra-individual differences became obvious, yet in each one of these SE-positive 
animals, only one or two of the samples exceeded the threshold level for SE. In two individuals SE was verified in both uterine horns (individual results: UB: $4 \%$ and 1.4\% PMN; RUH: $6.4 \%$ and 5\% PMN; LUH: 5.7\% and 5\% PMN), the third surpassed the threshold in the uterine body as well as in the right uterine horn (individual results: UB: 7.7\% PMN; RUH: 5.4\% PMN; LUH: 1.4\% PMN) and the other seven animals were diagnosed with SE only in the right (individual results: UB: 3.7\% and 3\% PMN; RUH: 5.4\% and 5.4\% PMN; LUH: 4.4\% and 4\% PMN) or left uterine horn (individual results: UB: $0.7 \%$, 2.7\% and 2.0\% PMN; RUH: 4\%, 3\% and 3.4\% PMN; LUH: 5\%, 6.7\% and 5\% PMN) or the uterine body (individual results: UB: 5\% and 6.7\% PMN; RUH: 0.4\% and 3\% PMN; LUH: 4.7\% and 4.4\% PMN).

\section{Conclusions}

The results demonstrate that it might be advisable, for safe diagnosis of subclinical endometritis in embryo donor cows or cows well past the postpartum period, to take at least two cytological samples from different intrauterine localizations, preferably the uterine horns. The cow should be seen as positive for SE if at least one sample exceeds the threshold level of 5\% PMN. A single exfoliative cytology does not seem to represent the entire endometrium. These findings might also be an argument to investigate this problem further using the low-volume flush technique, where a larger region of the endometrium is sampled.

Acknowledgments: The authors would like to thank the participating farmers, their personnel and all the other involved people for their support and help.

Author Contributions: Janna Egberts performed the experiments and statistical analysis. Jan Detterer supervised the experiments in the field, Jan Detterer and Arno Park were involved in cytobrush sampling. Janna Egberts, Jan Detterer and Sabine Meinecke-Tillmann participated in the interpretation of the results. Janna Egberts wrote the manuscript. Sabine Meinecke-Tillmann and Jan Detterer conceived and designed the experiments and provided editorial advice. Sabine Meinecke-Tillmann supervised the study.

Conflicts of Interest: The authors declare no conflict of interest.

\section{Abbreviations}

The following abbreviations are used in this manuscript:

SE subclinical endometritis

PMN polymorphonuclear neutrophils

UB uterine body

RUH right uterine horn

LUH left uterine horn

\section{References}

1. Sheldon, I.M.; Lewis, G.S.; LeBlanc, S.; Gilbert, R.O. Defining postpartum uterine disease in cattle. Theriogenology 2006, 65, 1516-1530. [CrossRef] [PubMed]

2. Kasimanickam, R.; Duffield, T.F.; Foster, R.A.; Gartley, C.J.; Leslie, K.E.; Walton, J.S.; Johnson, W.H. Endometrial cytology and ultrasonography for the detection of subclinical endometritis in postpartum dairy cows. Theriogenology 2004, 62, 9-23. [CrossRef] [PubMed]

3. Gilbert, R.O.; Shin, S.T.; Guard, C.L.; Erb, H.N.; Frajblat, M. Prevalence of endometritis and its effects on reproductive performance of dairy cows. Theriogenology 2005, 64, 1879-1888. [CrossRef] [PubMed]

4. Barański, W.; Podhalicz-Dzięgielewska, M.; Zduńczyk, S.; Janowski, T. The diagnosis and prevalence of subclinical endometritis in cows evaluated by different cytologic thresholds. Theriogenology 2012, 78, 1939-1947. [CrossRef] [PubMed]

5. Madoz, L.V.; Giuliodori, M.J.; Migliorisi, A.L.; Jaureguiberry, M.; de la Sota, R.L. Endometrial cytology, biopsy and bacteriology for the diagnosis of subclinical endometritis in grazing dairy cows. J. Dairy Sci. 2014, 97, 195-201. [CrossRef] [PubMed]

6. Prunner, I.; Wagener, K.; Pothmann, H.; Ehling-Schulz, M.; Drillich, M. Risk factors for uterine diseases on small- and medium-sized dairy farms determined by clinical, bacteriological, and cytological examinations. Theriogenology 2014, 82, 857-865. [CrossRef] [PubMed] 
7. Sens, A.; Heuwieser, W. Presence of Escherichia coli, Trueperella pyogenes, $\alpha$-hemolytic streptococci, and coagulase-negative staphylococci and prevalence of subclinical endometritis. J. Dairy Sci. 2013, 96, 6347-6354. [CrossRef] [PubMed]

8. Chapwanya, A.; Meade, K.G.; Narciandi, F.; Stanley, P.; Mee, J.F.; Doherty, M.L.; Callanan, J.J.; O'Farrelly, C. Endometrial biopsy: A valuable clinical and research toolin bovine reproduction. Theriogenology 2010, 73, 988-994. [CrossRef] [PubMed]

9. Madoz, L.V.; Giuliodori, A.L.; Jaureguiberry, M.; Plöntzke, J.; Drillich, M.; de la Sota, R.L. The relationship between endometrial cytology during estrous cycle and cutoff points for the diagnosis of subclinical endometritis in grazing dairy cows. J. Dairy Sci. 2013, 96, 4333-4339. [CrossRef] [PubMed]

10. Carvalho, P.D.; Souza, A.H.; Sartori, R.; Hackbart, R.S.; Dresch, A.R.; Vieira, L.M.; Baruselli, P.S.; Guenther, J.N.; Fricke, P.M.; Shaver, R.D.; et al. Effects of deep-horn AI on fertilization and embryo production in superovulated cows and heifers. Theriogenology 2013, 80, 1074-1081. [CrossRef] [PubMed]

11. Fernandez-Sanchez, F.I.; Barrio-Lopez, M.; Quintela-Arias, L.A.; Becerra-Gonzales, J.J.; Peña-Martinez, A.I.; Martinez-Bello, D.; Garcia-Herradon, P.; Perez-Marín, C.C. Use of endometrial cytology and metabolic profiles for selection of embryo donor cows. Span. J. Agric. Res. 2014, 12, 664-671. [CrossRef]

12. Kasimanickam, R.; Duffield, T.F.; Foster, R.A.; Gartley, C.J.; Leslie, K.E.; Walton, J.S.; Johnson, W.H. A comparison of the Cytobrush and uterine lavage techniques to evaluate endometrial cytology in clinically normal postpartum dairy cows. Can. Vet. J. 2005, 46, 255-259. [PubMed]

13. Bonnett, B.N.; Miller, R.B.; Martin, S.W.; Etherington, W.G.; Buckrell, B.C. Endometrial biopsy in Holstein-Friesioan dairy cows II. Correlations between Histological Criteria. Can. J. Vet. Res. 1991, 55, 162-167. [PubMed]

14. Schmauder, S.; Weber, F.; Kiossis, E.; Bollwein, H. Cyclic changes in endometrial echotexture of cows using a computer-assisted program for the analysis of first- and second-order grey level statistics of B-Mode ultrasound images. Anim. Reprod. Sci. 2007, 106, 153-161. [CrossRef] [PubMed]

15. LeBlanc, S.J. Reproductive tract inflammatory disease in postpartum dairy cows. Anim. Cons. 2014, 8, 54-63. [CrossRef] [PubMed]

(C) 2016 by the authors; licensee MDPI, Basel, Switzerland. This article is an open access article distributed under the terms and conditions of the Creative Commons Attribution (CC-BY) license (http://creativecommons.org/licenses/by/4.0/). 